\title{
Effects of Acute Supplementation of Panax ginseng on Endurance Performance in Healthy Adult Males of Kolkata, India
}

\author{
Ishita Bhattacharjee, Amit Bandyopadhyay*
}

\section{Ishita Bhattacharjee, Amit Bandyopadhyay*}

Sports and Exercise Physiology Laboratory, Department of Physiology, University of Calcutta, University Colleges of Science and Technology, Kolkata, West Bengal, INDIA.

\section{*Correspondence}

Dr. Amit Bandyopadhyay, M.Sc., Ph.D., FICN

Assistant Professor, Sports and Exercise Physiology Laboratory, Department of Physiology, University of Calcutta, University Colleges of Science and Technology, 92, A.P.C. Road-700009, Kolkata, West Bengal, INDIA.

Phone: +91 8334870640

Email: bamit74@yahoo.co.in

\section{History}

- Submission Date: 17-04-2020;

- Review completed: 19-05-2020;

- Accepted Date: 15-06-2020.

DOI : 10.5530/ijcep.2020.7.2.16

Article Available online

http://www.ijcep.org

\section{Copyright}

(C) 2020 Phcog. Net. This is an openaccess article distributed under the terms of the Creative Commons Attribution 4.0 International license.

\begin{abstract}
Background and Aim: Panax ginseng C. A. Meyer (PG), a worldwide renowned "adaptogen", is believed to combat stress and augment endurance performance. Studies available regarding chronic supplementation of PG revealed contradictory findings. This study, for the first time, was conducted to examine the effects of acute supplementation of PG on endurance performance in healthy sedentary male university students of Kolkata, India. Methods: In this placebo controlled double blind study, effects of acute supplementation (1 hr before endurance exercise) of $200 \mathrm{mg}$ PG on endurance exercise was examined in healthy males $(n=12)$, age ranging from 20 to 24 years. Endurance time, heart rate and rate of perceived exertion (RPE) were recorded. Blood samples were drawn just before supplementation and at the time of exhaustion for biochemical analysis of glucose, insulin, lactic acid, free fatty acid, lipid peroxidase, catalase, superoxide dismutase and total thiol. Data were analyzed by paired $t$-test, one-way ANOVA with post-hoc test. Results: Endurance time was significantly higher $(p<0.001)$ in PG-trial $(96.17 \pm 1.19 \mathrm{~min})$ compared to placebo (PL) trial $(92.42 \pm 1.24 \mathrm{~min})$. Heart-rate and RPE at the time of exhaustion in PL-trial were significantly greater $(p<0.05)$ than PG-trial. Post-exercise values of lactic acid, free fatty acid, lipid peroxidase were significantly greater $(p<0.05)$ in placebo trial than PG trial while post-exercise values of glucose $(78.96 \pm 1.67 \mathrm{mg} / \mathrm{dl})$, insulin $(3.13 \pm 0.56 \mu \mathrm{U} / \mathrm{ml})$, catalase (78.02 $\pm 1.38 \mu \mathrm{mol}$ of $\mathrm{H}_{2} \mathrm{O}_{2} / \mathrm{min} / \mathrm{mg}$ of protein), superoxide-dismutase $(22.41 \pm 1.24 \mathrm{nmol} / \mathrm{mg}$ of protein) and total thiol $(23.42 \pm 1.09 \mu \mathrm{mol} / \mathrm{L})$ of $\mathrm{PG}$-trial were significantly greater $(p<0.05)$ than that of PL trial $\left(75.33 \pm 1.5 \mathrm{mg} / \mathrm{dl}, 1.71 \pm 0.34 \mu \mathrm{U} / \mathrm{ml}, 75.84 \pm 0.92 \mu \mathrm{mol}\right.$ of $\mathrm{H}_{2} \mathrm{O}_{2} / \mathrm{min} / \mathrm{mg}$ of protein, $19.36 \pm 1.45 \mathrm{nmol} / \mathrm{mg}$ of protein and $18.85 \pm 1.25 \mu \mathrm{mol} / \mathrm{L}$ respectively). Conclusion: Thus, acute supplementation of $200 \mathrm{mg}$ PG has ergogenic effect in studied population.
\end{abstract}

Key words: Antioxidant property, Endurance exercise, Ergogenic aid, Ginsengosides, Oxidative stress.

\section{INTRODUCTION}

Panax ginseng C. A. Meyer (in 1833) (PG), a deciduous perennial herb (Araliaceae family), has a revered history for its traditional worldwide use as a tonic that maintains life energy in Asian countries like Korea, Japan and is available in the form of whole root, root powder and standardized root extracts (powder). ${ }^{[1]} \mathrm{PG}$ is widely considered as an 'adaptogen' which can combat stress and augment endurance performance. ${ }^{[2]}$ The major active ingredients of PG are ginsenosides which have been reported to have effects on nervous system, immunomodulation and nitric oxide release. ${ }^{[3]}$ Though actual mechanism of all these actions of PG has not been clearly identified, yet, the mostly accepted theory is by the activation of hypothalamo-hypophysealadrenocortical axis. ${ }^{[3]}$ Animal toxicity studies revealed that PG was very safe with no teratogenicity or mutagenicity. ${ }^{[3]} \mathrm{PG}$ was not enlisted as banned ergogenic aid for athletes. ${ }^{[3]}$ Ingestion of $200 \mathrm{mg}$ of PG per day has been recommended as safe. ${ }^{[4]}$

Studies indicated chronic PG supplementation augmented post-exercise recovery, increased free fatty acid (FFA) level, retained glucose level during exercise, increased glycogen storage in the liver and skeletal muscle and ultimately enhanced endurance performance ${ }^{[3,5]}$ while other investigations reported contradictory findings. ${ }^{[1,6-9]}$ So it was quite justified to speculate that acute supplementation of PG might have similar outcomes. To our knowledge only one study has been conducted till date on the effects of acute supplementation of PG on endurance performance, that also on different population not in Indian perspective. ${ }^{[1]}$

Hence this might be the first study on the effects of acute supplementation of PG on endurance performance to explore the effect in Indian population. Moreover, the status of oxidative stress generated out of endurance exercise following acute supplementation of PG has not yet been explored.

Cite this article: Bhattacharjee I, Bandyopadhyay A. Effects of Acute Supplementation of Panax ginseng on Endurance Performance in Healthy Adult Males of Kolkata, India. Int J Clin Exp Physiol. 2020;7(2):63-8. 
The present study was therefore aimed to investigate the effects of acute supplementation of PG on endurance capacity and heart rate (HR), biochemical parameters such as glucose, insulin, FFA, blood lactate and superoxide dismutase (SOD), catalase, LPO (lipid peroxidase), total thiol in Male University students of Kolkata, India.

\section{MATERIALS AND METHODS}

\section{Subject Recruitment Procedures}

From the University of Calcutta, twelve male post-graduate students of mean age of $22.0 \pm 1.41$ yrs, mean body mass of $62 \pm 3.1 \mathrm{~kg}$, mean body height of $168 \pm 0.06 \mathrm{~cm}$ and mean BMI of $22.04 \pm 1.6 \mathrm{~kg} / \mathrm{m}^{2}$ and with similar socio-economic background were recruited in the study by simple random sampling method. All the subjects were non-user of PG, nonsmoker and they neither had history of any illnesses like hypertension, asthma, diabetes, etc. nor taking any medication during the study.

\section{Sample Size Calculation}

The sample size was calculated by using PS Power and sample size calculation version 3.0. ${ }^{[10]}$ Previous data indicated that the difference in the response of matched pairs was normally distributed with standard deviation $(\sigma) 6{ }^{[1]}$ Confidence interval, $\alpha$ and $\delta$ were set at $95 \%, 0.5$ and 5 , respectively. The number of subjects thus calculated was nine. ${ }^{[9]}$ Considering 25\% drop out, the calculated minimum sample size was 12 . Thus the present study was conducted on 12 subjects.

The ethical clearance for the research work was approved by the Human Ethics Committee, University of Calcutta and written informed consent was obtained from all the participants.

\section{Doses}

It has been recommended that 200mg of PG supplementation is most effective, safe and beneficial to physiological responses as this dose gives the optimal and similar response as its higher doses. ${ }^{[1]}$ It was supplemented orally $1 \mathrm{hr}$ before the exercise trial. ${ }^{[1]}$ Artificial-sweetener (zero-calorie substance) was used as placebo (PL). Both supplements were dissolved in $250 \mathrm{ml}$ of plain water and were ingested $1 \mathrm{hr}$ before the exercise trial. The supplements were supplied in opaque bottles to avoid any visible difference between them.

\section{Experimental Design}

The experiment was conducted in self-controlled double-blind method. Each subject visited the laboratory after overnight fasting (12 hr) at 8:00am for 5 times. Pre-experimental trials were conducted during the first three visits while experimental trials with two different supplements, i.e., PG and PL were conducted in the last two visits. At least a period of 4 days gap was maintained between these successive experimental trials. Minimum 7 days gap was retained between pre-experimental trial and experimental trial protocols (Figure 1).

\section{Preparation of Subjects}

Subjects were instructed to abstain from heavy exercise for $24 \mathrm{hr}$ ahead of the days of the trials. Their food chart and physical activity for the last 3 days prior to the first trial were documented and the same diet was followed for the last 3 days before the consecutive trials, to diminish the inequality of muscle glycogen level prior to exercise. They were reminded to make sure about conformity. ${ }^{[1]}$

\section{Pre-experimental Trial Protocol}

The pre-experimental trial protocol was conducted to introduce the subject to exercise trial protocol and also to decide the speed of the treadmill at which the subject attained his $80 \%$ of $\mathrm{HR}_{\max }$ or age predicted heart rate $(220$ - Age). At first, the subject went through a series physical examination procedure like evaluation of $\mathrm{HR}, \mathrm{BP}, \mathrm{ECG}$, height, weight to confirm that he was physically fit to take part in the trial. Warm-up was given in the form of running in treadmill at $5 \mathrm{~km} / \mathrm{h}$ at $0 \%$ elevation for 5 min. HR was measured at an interval of $10 \mathrm{~min}$ during exercise.

\section{Trial Protocol}

On arrival of the subject to the laboratory at $8 \mathrm{am}$, after $12 \mathrm{hr}$ of overnight fasting, the subject underwent physical examination similar to that of pre-experimental trial protocol. He was given $500 \mathrm{ml}$ of plain water and a bread slice. ${ }^{[1]}$ Polar HR monitor and skin thermistors were secured for recording of $\mathrm{HR}$ (during the rest as well as during the exercise trials) and body-temperature respectively (Figure 2).

\section{During the Experiment}

$1 \mathrm{hr}$ prior to exercise $(0 \mathrm{~min}), 8 \mathrm{ml}$ blood was drawn from the antecubital vein of the subject. Then supplementation (either $200 \mathrm{mg}$ PG or PL dissolved in $250 \mathrm{ml}$ water) was given to the subject and was allowed to take rest for $1 \mathrm{hr}$. After $1 \mathrm{hr}$, subject was asked to do warm-up at speed of $5 \mathrm{~km} / \mathrm{h}$ for $5 \mathrm{~min}$ following which the subjects performed in treadmill at their specified speed. The exercise continued till subjects' volitional exhaustion regardless of verbal encouragement along with accomplishment of peak HR that should had reached his $\mathrm{HR}_{\max } \pm 10$ beats. $8 \mathrm{ml}$ blood sample was collected again from the antecubital vein at exhaustion. HR and RPE (Borg's Scale) were recorded at an interval of 10 mins. When the subject stopped running, he was asked to cool down for 2-3 min on treadmill at a walking speed of $4-6 \mathrm{~km} / \mathrm{h}$.

\section{After the Experiment}

Body mass was recorded after the test. In a proportion of $450 \mathrm{ml}$ of water was given to the subject for every $0.45 \mathrm{~kg}$ loss of body weight to replenish water loss during exercise. ${ }^{[11]}$ Each subject repeated the same procedure for the subsequent trial.

\section{Biochemical Parameters}

$8 \mathrm{ml}$ of venous blood was drawn during each blood sampling of which $1 \mathrm{ml}$ was kept in EDTA vacutainer for the analysis of plasma lactate (LA) and remaining $7 \mathrm{ml}$ was transferred to a normal vial for separation of serum and estimation of glucose, insulin, FFA, LPO, SOD, catalase and total thiol. Oxidative stress was determined by LPO product in the form of thiobarbituric acid reactive substances (TBARS), enzymatic assessment of antioxidants was carried out for SOD, catalase and total thiol.

\section{Estimation of Total Protein}

Total protein present in the serum was determined by the method of Lowry et al. ${ }^{[12]}$

\section{Estimation of Glucose}

Plasma glucose was assayed by UV test enzymatic reference method with hexokinase on Roche/Hitachi cobas c 311 systems $^{[13,14]}$ and was measured photometrically at $340 \mathrm{~nm}$. The values were expressed in units $\mathrm{mmol} / \mathrm{L}$.

\section{Estimation of Insulin}

Following the method of Sapin et al. ${ }^{[15]}$ serum insulin was measured by electrochemiluminescence immunoassay using Roche Elecsys Insulin 2010 reagent kit, Catalog number 12017547122 (100 determinations) Roche Diagnostics Corporation, Indianapolis, IN 46250. ${ }^{[15]}$ The Elecsys Insulin assay consists of two monoclonal antibodies which were specific for human insulin. The values were expressed in $\mu \mathrm{U} / \mathrm{L}$. 


\section{Estimation of Plasma Free Fatty Acid}

Estimation of serum free fatty acid was accomplished by the method of Kwon and Rhee. ${ }^{[16]}$ Following the method of Lowry and Tinsley, a copper reagent was prepared. An aqueous solution of cupric acetate (blue coloured) was also prepared [5\% (w/v), pH 6.1 by using pyridine] and it was filtered. ${ }^{[17]}$ The standard curves of free fatty acids vs absorbance were determined by measuring the absorbance of isooctane solution at $715 \mathrm{~nm}$ against the control, which contains no free fatty acids. The values were expressed in units $\mathrm{mmol} / \mathrm{L}$.

\section{Estimation of Superoxide Dismutase}

SOD was determined by the method of Marklund and Marklund. ${ }^{[18]}$ The enzyme activity was measured at $420 \mathrm{~nm}$ and was expressed as units/mg of protein.

\section{Estimation of Catalase}

The catalase activity was assessed according to the method of Claiborne. ${ }^{[19]}$ The catalase activity was calculated in terms of $\mathrm{nmol}_{2} \mathrm{O}_{2}$ consumed/minute/mg protein.

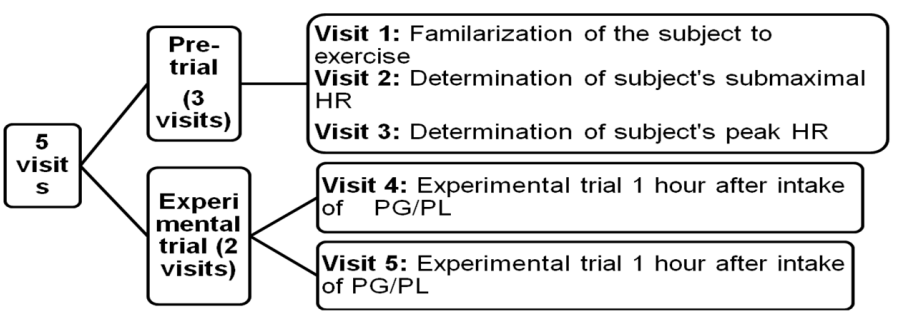

PL-Placebo; PG- Panax ginseng; HR- heart rate

Figure 1: Design of the study.

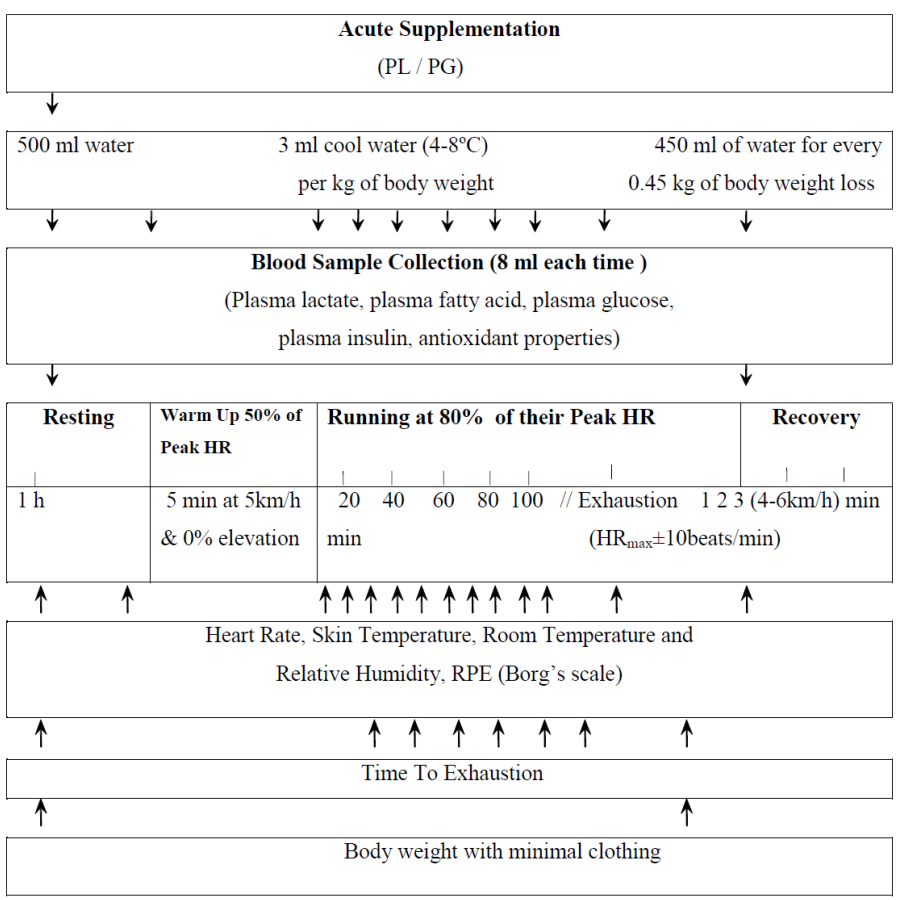

PL-Placebo; PG- Panax ginseng; HR- Heart rate; BPM- Beats per minute Figure 2: Experimental trial Protocol.

\section{Estimation of Lipid Peroxidation}

According to the method of Wright et al. ${ }^{[20]}$ LPO was estimated. The color of the TBARS containing supernatant was measured at $535 \mathrm{~nm}$. The result was expressed as nmol of MDA formed per mg of protein. ${ }^{[20]}$

\section{Estimation of Total Thiol}

Total thiol levels were assessed by Ellman's method. A reaction occurred between thiols and DTNB which was recorded at $412 \mathrm{~nm} .^{[21]}$

\section{Estimation of Lactate}

Calorimetric determination of lactate in human plasma was estimated by the method of Barker and Summerson. ${ }^{[22]}$ Lactic acid was converted into acetaldehyde in presence of concentrated sulfuric acid and the color of acetaldehyde was measured at $560 \mathrm{~nm}$ after its reaction with p-hydroxydiphenyl in the presence of cupric ions.

\section{Statistical Analysis of Data}

Normal distribution of the data was done by Shapiro-Wilk Test. All data were expressed as mean \pm standard deviation (SD). Evaluation of significant differences in all parameters between PG and PL trial was done by paired $t$-test. Confidence interval was set as $95 \%$. One way ANOVA was performed to test whether any significant difference exists in HR and RPE values obtained within the trial at various time intervals. Bonferroni post-hoc analysis was also performed. Level of significance for all analysis was set at $p<0.05$.

\section{RESULTS}

The age of the subjects were documented from the National ID Card issued by the Government of India. The mean height was $168.0 \pm 0.06 \mathrm{~cm}$ and the mean body mass was $62 \pm 3.1 \mathrm{~kg}$, measured to an accuracy of \pm 0.1 $\mathrm{kg}$ by weighing machine fitted with height measuring rod (Avery India Ltd., India). Body mass index (BMI) was $22.04 \pm 1.6 \mathrm{~kg} . \mathrm{m}^{-2}$. The systolic and diastolic BP of the subjects were $115.83 \pm 5.07$ and $80.33 \pm 2.34 \mathrm{~mm}$ $\mathrm{Hg}$ respectively. The resting HR and HRmax of the subjects were $70 \pm 1.12$ and $198.7 \pm 1.1$ beats. $\mathrm{min}^{-1}$ respectively. All values were expressed as mean \pm SD. There was no significant alteration in room temperature (29$33^{\circ} \mathrm{C}, 30-32^{\circ} \mathrm{C}$, respectively) and relative-humidity (64-84 and $65-87 \%$ respectively) between PL and PG trials.

Running time to exhaustion was significantly $(p<0.001)$ higher in PG trial $(96.17 \pm 1.19 \mathrm{~min})$ than PL trial $(92.42 \pm 1.24 \mathrm{~min})$ (Figure 3).

Heart rate increased significantly $(p<0.05)$, over time in same experimental trial compared to respective pre-exercise value (Table 1). Exercise HR of PG trial were significantly $(p<0.05)$ lower than PL trials (Table 1).

Subjects expressed the level of their exhaustion on a numerical scale (RPE by Borg's Scale) to indicate the fatigue level (Table 1). RPE increased significantly $(p<0.05)$ with the progression of duration of exercise in both the trials. PG trial showed significantly $(p<0.05)$ lower RPE than PL trial (Table 1).

Pre and post-exercise concentrations of blood lactate, glucose, insulin, free fatty acid, LPO, SOD, catalase and total thiol for both PG and PL trials have been presented in Table 2. There was a significant $(p<0.05)$ difference in plasma lactate, plasma glucose, insulin, FFA, SOD, LPO, catalase and total thiol concentrations between PL and PG trials as well as between pre- and post- exercise values of respective trial (Table 2).

\section{DISCUSSION}

PG was well known to improve the endurance capacity, strength and immune system without any harmful effects to the body. ${ }^{[3]}$ In the present study, the endurance running time increased significantly $(p<0.05)$ in 


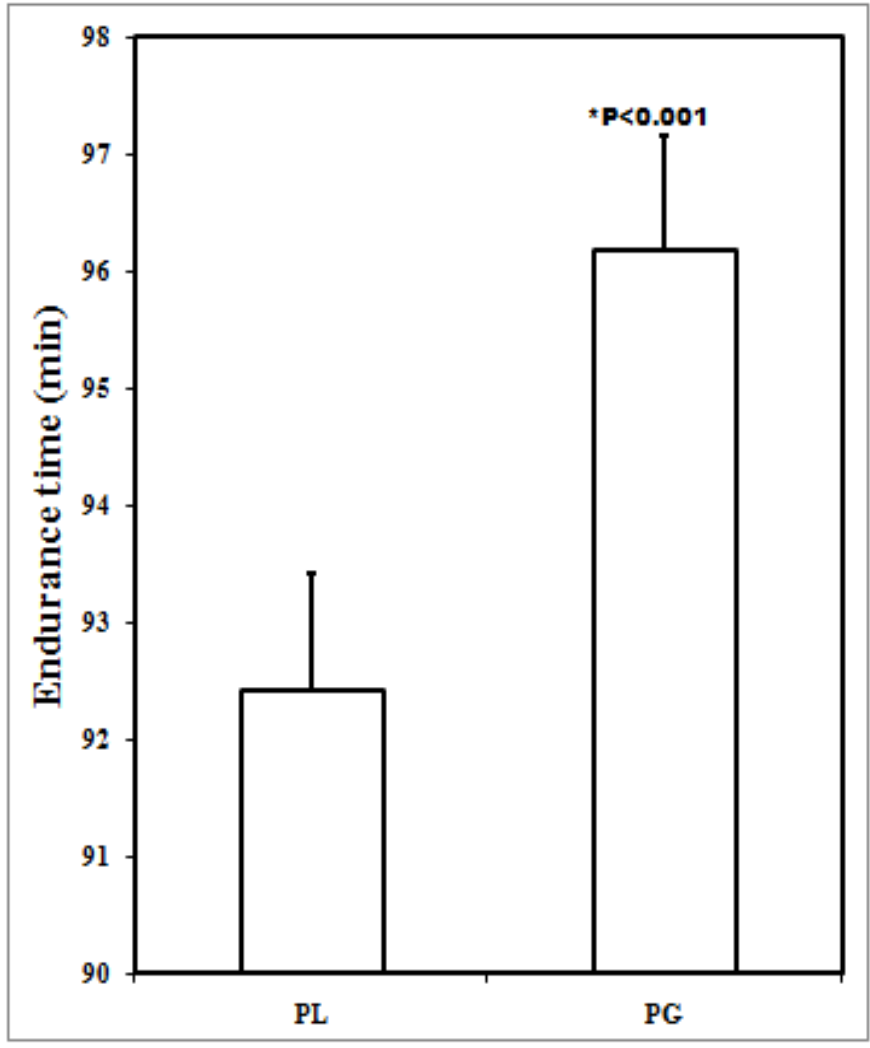

Figure 3: Endurance time in PL and PG trials.
PG than PL trial as also reported in a study. ${ }^{[3]}$ Oxygen uptake was not measured in this investigation. Another study reported an elevation of endurance time in healthy males. ${ }^{[23]}$ However, contradictory findings were also depicted in some other studies. ${ }^{[1,7]}$ Acute supplementation of PG at a dose of $200 \mathrm{mg}$ also did not bring any significant change in endurance performance in Malaysian recreational male athlete. ${ }^{[1]}$ However, a recent study established ergogenic effect of PG. ${ }^{[24]}$ In the present study, acute supplementation of $200 \mathrm{mg}$ of PG augmented endurance performance. Though the exact mechanism behind the performance enhancing effect of PG is not clear, but it was possibly due to its adaptogenic properties, testosterone-like effect, stimulating effect on CNS, enhanced production of in-vivo testosterone, anti-stress property, amplifies the activities of enzymes related to oxidative phosphorylation, increased oxygen transport and extraction to the exercising muscles, its influence on metabolism of carbohydrate and fat along with immune and endocrine functions. ${ }^{[2,6,25]}$

In the present investigation, pre-exercise and exercise HR of PG trial were significantly $(p<0.05)$ lower than those of PL trial. This finding is in agreement with earlier study. ${ }^{[5]}$ The exercise HR increased significantly $(p<0.05)$ compared to their respective pre-exercise values till the completion of both the PG and PL exercise trials to meet increasing demand of the body during physical exercise. There were other researchers who didn't find any beneficial effect of PG supplementation on exercise heart rate. ${ }^{[7]}$ In the present study, the decrease in exercise HR might be due to the fact that constituents of ginsenosides present in PG can lead to bradycardia which was evident from previous animal studies. ${ }^{[6]}$ This in turn improved oxygen utilization by the working muscles and thereby endurance performance. ${ }^{[5,6]}$

Table 1: Exercise heart rates and RPE in PG and PL trials $(n=12)$.

\begin{tabular}{|c|c|c|c|c|c|c|c|c|c|c|c|c|c|c|}
\hline \multirow[b]{2}{*}{$\begin{array}{l}\text { Parameters } \\
\text { Measured }\end{array}$} & \multirow[b]{2}{*}{ Sup } & \multicolumn{12}{|c|}{ Exercise Duration (min) } & \multirow{2}{*}{$\begin{array}{c}\text { F- Value } \\
\text { (p-value) } \\
\text { [df 1-11, } \\
\text { df 2-132] } \\
\text { [df 1-9, } \\
\text { df 2-110]* }\end{array}$} \\
\hline & & 0 & 5 & 10 & 20 & 30 & 40 & 50 & 60 & 70 & 80 & 90 & Exhaustion & \\
\hline Exercise & PL & $\begin{array}{r}72.92 \\
\pm 1.08\end{array}$ & $\begin{array}{l}118.08 \\
\pm 1.08^{*}\end{array}$ & $\begin{array}{c}147.83 \\
\pm 2.17 \\
*\end{array}$ & $\begin{array}{c}166.08 \\
\pm 2.02 \\
*\end{array}$ & $\begin{array}{c}174.33 \\
\pm 2.43 \\
*\end{array}$ & $\begin{array}{l}179.58 \\
\pm 2.75^{*}\end{array}$ & $\begin{array}{c}185.75 \\
\pm 1.77 \\
*\end{array}$ & $\begin{array}{c}192.08 \\
\pm 2.02 \\
*\end{array}$ & $\begin{array}{c}196.33 \\
\pm 2.93 \\
\star\end{array}$ & $\begin{array}{c}202.00 \\
\pm 2.09 \\
*\end{array}$ & $\begin{array}{c}209.58 \\
\pm 1.93 \\
*\end{array}$ & $\begin{array}{c}215.42 \pm 2.07 \\
*\end{array}$ & $\begin{array}{c}4683.248 \\
(0.000)\end{array}$ \\
\hline $\begin{array}{c}\text { HR } \\
\text { (beats/min) }\end{array}$ & PG & $\begin{array}{c}69.75 \\
\pm 1.22 \\
\quad \#\end{array}$ & $\begin{array}{c}113.92 \\
\pm 1.08 \\
* \#\end{array}$ & $\begin{array}{c}144.00 \\
\pm 2.26 \\
* \#\end{array}$ & $\begin{array}{c}159.83 \\
\pm 2.17 \\
{ }_{\#}\end{array}$ & $\begin{array}{c}169.50 \\
\pm 2.43 \\
\star \#\end{array}$ & $\begin{array}{c}175.00 \\
\pm 2.22 \\
{ }^{\star} \#\end{array}$ & $\begin{array}{c}180.33 \\
\pm 2.81 \\
\star \#\end{array}$ & $\begin{array}{c}186.92 \\
\pm 3.15 \\
* \#\end{array}$ & $\begin{array}{c}190.33 \\
\pm 2.02 \\
* \#\end{array}$ & $\begin{array}{c}197.92 \\
\pm 2.71 \\
{ }^{*}\end{array}$ & $\begin{array}{c}207.08 \\
\pm 2.13 \\
\star \#\end{array}$ & $\begin{array}{c}211.50 \pm 2.35 \\
* \#\end{array}$ & $\begin{array}{c}3840.592 \\
(0.000)\end{array}$ \\
\hline & PL & ------ & -.- & $\begin{array}{c}9.67 \\
\pm 1.07\end{array}$ & $\begin{array}{c}10.58 \\
\pm 0.996\end{array}$ & $\begin{array}{l}11.83 \\
\pm 0.94\end{array}$ & $\begin{array}{l}12.67 \\
\pm 1.07\end{array}$ & $\begin{array}{l}13.83 \\
\pm 0.94\end{array}$ & $\begin{array}{c}15.67 \\
\pm 1.07 \\
\mu\end{array}$ & $\begin{array}{l}16.00 \\
\pm 1.12\end{array}$ & $\begin{array}{c}17.58 \\
\pm 0.996 \\
\mu\end{array}$ & $\begin{array}{l}18.67 \\
\pm 1.07\end{array}$ & $19.00 \pm 0.95$ & $\begin{array}{l}127.027 \\
(0.000)\end{array}$ \\
\hline
\end{tabular}

Values were expressed as mean \pm SD; PG: Panax ginseng trial; PL: Placebo trial; Sup: Supplementation given; HR: Heart rate; RPE: Rate of perceived exertion.

${ }^{*} p<0.05$ Compared working HR with pre-exercise $(0 \mathrm{~min}) \mathrm{HR}$ value in the same trial.

${ }^{*} p<0.05$ Compared pre-exercise HR and working HR of PG trials with their respective values of PL trial.

${ }^{s} p<0.05$ when compared RPE values between PL with PG.

${ }^{\mu} p<0.05$ when compared RPE values at a specific time with the previous time in the same trial.

${ }^{\epsilon}$ Degrees of freedom for exercise heart rates

${ }^{¥}$ Degrees of freedom for RPE. 
Table 2: Values of different blood parameters during the experimental trials $(n=12)$.

\begin{tabular}{|c|c|c|c|}
\hline $\begin{array}{l}\text { Biochemical } \\
\text { Parameters }\end{array}$ & Supplementation & Pre-exercise & Post-exercise \\
\hline \multirow{2}{*}{ Glucose (mg/dl) } & PL & $80.69 \pm 1.12$ & $75.33 \pm 1.5^{\star}$ \\
\hline & PG & $80.78 \pm 1.38$ & $78.96 \pm 1.67^{\star} \#$ \\
\hline \multirow{2}{*}{ Insulin $(\mu \mathrm{U} / \mathrm{ml})$} & PL & $6.96 \pm 0.88$ & $1.71 \pm 0.34^{*}$ \\
\hline & PG & $7.14 \pm 0.58$ & $3.13 \pm 0.56^{\star} \#$ \\
\hline \multirow{2}{*}{$\mathrm{LA}(\mathrm{mmol} / \mathrm{L})$} & $\mathrm{PL}$ & $1.81 \pm 0.46$ & $5.35 \pm 0.67^{\star}$ \\
\hline & PG & $1.75 \pm 0.43$ & $2.95 \pm 0.42^{\star} \#$ \\
\hline \multirow{2}{*}{ FFA (mmol/L) } & PL & $0.58 \pm 0.10$ & $1.28 \pm 0.15^{\star}$ \\
\hline & PG & $0.57 \pm 0.13$ & $1.08 \pm 0.12 * \#$ \\
\hline \multirow{2}{*}{$\mathrm{LPO}(\mu \mathrm{mol} / \mathrm{L})$} & PL & $1.12 \pm 0.18$ & $1.91 \pm 0.24^{*}$ \\
\hline & PG & $1.10 \pm 0.13$ & $1.36 \pm 0.19^{*} \#$ \\
\hline \multirow{2}{*}{$\begin{array}{c}\text { CAT ( } \mu \text { mol of } \\
\mathrm{H}_{2} \mathrm{O}_{2} / \mathrm{min} / \mathrm{mg} \text { of } \\
\text { protein) }\end{array}$} & PL & $71.09 \pm 0.92$ & $75.84 \pm 0.92^{*}$ \\
\hline & PG & $70.79 \pm 0.89$ & $78.02 \pm 1.38^{\star} \#$ \\
\hline \multirow{2}{*}{$\begin{array}{l}\mathrm{SOD}(\mathrm{nmol} / \mathrm{mg} \text { of } \\
\text { protein) }\end{array}$} & PL & $16.52 \pm 1.30$ & $19.36 \pm 1.45^{*}$ \\
\hline & PG & $16.28 \pm 0.87$ & $22.41 \pm 1.24^{*} \#$ \\
\hline \multirow{2}{*}{ Total Thiol $(\mu \mathrm{mol} / \mathrm{L})$} & PL & $15.97 \pm 0.69$ & $18.85 \pm 1.25^{\star}$ \\
\hline & PG & $16.07 \pm 1.09$ & $23.42 \pm 1.09^{\star} \#$ \\
\hline
\end{tabular}

Values were expressed as mean $\pm \mathrm{SD}$;

PG: Panax ginseng trial; PL: Placebo trial; FFA: Free Fatty Acid; SOD: Superoxide Dismutase, LPO: Lipid Peroxidase; LA: Plasma Lactate.

${ }^{*} p<0.05$ when compared post exercise value with pre-exercise value in the respective trial.

${ }^{\#} p<0.05$ when compared between post-exercise values of PL and PG trial.

The RPE score in the present study was significantly lower in PG than PL trial $(p<0.05)$. This is in agreement with earlier study but contradictory to some other findings. ${ }^{[5,7]} \mathrm{RPE}$ was greatly associated with $\mathrm{HR}$ and pulmonary ventilation. ${ }^{[26]}$ Significantly $(p<0.05)$ lower values of exercise HR in PG trial could be one of the probable reasons behind it. An increase in oxygen uptake by the exercising muscles as well as antioxidant properties of PG probably aided in lowering of RPE which could have been established if the two parameters (respiration and ventilation) were also measured. However, it is a major drawback of the study that oxygen uptake parameter could not be measured in this study. Other reasons behind reduction in RPE might also be owing to the adaptogenic property of PG which combat stress by decreased secretion of cortisol (via changes in circulating ACTH) through hypothalamo-hypophysealadrenal axis, immune-modulatory functions and enhanced cognitive effect. $^{[2,25,26]}$

Endurance exercise results in decrease in blood glucose level. In the present study, the decrease in blood glucose level following exercise trial was significantly higher in placebo trial than PG trial. Acute supplementation of PG prevented the reduction of blood glucose level and helped to maintain the post exercise value significantly $(p<0.05)$ higher than the PL trial, also supported by another study. ${ }^{[27]}$ Ginsenosides present in PG might had modified temporarily the choice of utilizing FFA over glucose or stored glycogen, thereby preserving blood glucose level. ${ }^{[2]}$ Contradictory findings showing insignificant change in blood glucose after PG ingestion was also reported. ${ }^{[28]}$ This could be related to the information that PG exerted potential effect mainly on stressed condition rather than normal, in this case which was physical exercise. ${ }^{[25]}$ The post-exercise level of insulin was significantly $(p<0.05)$ higher in PG than PL trial. It might be due to the alteration in glucose uptake or its utilization, or by any change in insulin uptake. ${ }^{[2]}$ It was reported that PG augmented synthesis of insulin and also played a role in cutting down the number of pancreatic cell death which was also observed that PG supplementation increased insulin sensitivity. ${ }^{[29]}$ This increase in insulin sensitivity might be induced by Compound $\mathrm{K}$ ginsenosides that possesses the capability of activating a vital signaling pathway of insulin resistance. ${ }^{[30]}$ However, contradictory findings were also reported in other studies. ${ }^{[27,27]}$

A significant increase $(p<0.05)$ in plasma lactate concentration from the commencement till fatigue was noted during exercise in both the trials compared to their corresponding resting values. This could be either due to more lactate production or its decreased wash out or combination of both the factors combined together. ${ }^{[1]}$ But blood lactate level was significantly lower in PG trial than PL trial $(p<0.05)$ possibly as a result of better utilization of muscular oxygen, or decreased production of plasma lactate during exercise might be due to better oxygen transport to the exercising muscles, which was in agreement with earlier findings. ${ }^{[5]}$ However, contradictory findings were also reported in different populations. ${ }^{[7]}$

There was a significant $(p<0.05)$ increase in FFA at the end of the exercise trial compared to their corresponding resting values in both the trials. Such steady increase indicated the availability of the substrate (fat) for its utilization as the major energy source during the endurance running trials. PG trial has shown significant $(p<0.05)$ increased plasma FFA than PL trial. Previous studies also suggested that PG showed a beneficial role on fuel homeostasis by sparing muscle glycogen, promoting FFA oxidation (lipolysis) and inhibiting lipogenesis during endurance exercise, thus enhancing exercise performance. ${ }^{[31]}$

Exercise induced oxidative stress was estimated by serum levels of LPO, SOD, catalase and total thiol. In this study, serum level of LPO decreased significantly $(p<0.05)$ in PG than PL trial, thereby reducing the lipid peroxidation of cells whereas the levels of antioxidant enzymes (SOD, catalase and total-thiol) were found to be increased significantly $(p<0.05)$ in PG than PL trial for combating with this exercise induced oxidative stress. This observation was in agreement with the previous studies. ${ }^{[23,32]}$ Though the exact mechanism of this antioxidant activity of PG is not clear yet, maltol, a phenolic component of PG along with other ginsenosides ( $\mathrm{Rb} 1, \mathrm{Rb} 2 \mathrm{etc}$.) might play a crucial role in the antioxidant property of PG. ${ }^{[2]} \mathrm{PG}$ induced increase in nitric-oxide synthesis could have an indirect relationship of this property of PG..$^{[2]}$

Previously PG was considered as a tonic which restores life energy mainly for the elderly, stressed or energy compromised population. But in the present study for the first time it was observed that acute supplementation of PG could be a performance enhancer. The finding of this study might popularize PG as an ergogenic aid during exercise among healthy population. The mechanism by which PG improve endurance performance might apparently include its ability in enhancing creatine synthesis within the body, influencing carbohydrate and lipid metabolism, anabolic functions such as synthesis of DNA, RNA and proteins, possessing biological active properties like adaptogenic, anti-stress, anti-fatigue, anti-hypertensive and antioxidant, vasodilation, bradycardia, as well as efficacy in improved psychomotor performance. ${ }^{[3,31]}$ From the discussion of this study, it could be postulated that the active ingredients in PG were sufficiently absorbed during the trials to elicit positive effects among recreational runners. There were differences in opinions among different studies, which might be due to difference in study design of those studies, lack of availability of 
uncontaminated supplement, mode of supplementation given, changes in exercise protocol, number of subject etc.

\section{CONCLUSION}

It is concluded from the present investigation that acute supplementation of $200 \mathrm{mg}$ of PG, one hour prior to the exercise exerted significant effect on the physiological parameters measured during the endurance running by ameliorating exercise induced oxidative stress and thereby augmenting exercise performance.

\section{Application of the work}

Endurance exercise performance can be increased by PG feeding. PG is a natural herb which aids to sustain blood glucose and insulin level required for strenuous exercise. Its antioxidant enzymes help to reduce oxidative stress. Hence it can acts as potent energy drink prior to exercise for optimum exercise performance.

\section{ACKNOWLEDGEMENT}

Authors are indebted to all the participants for their wholehearted support for executing the study and also to the phlebotomist who efficiently performed his work.

\section{CONFLICT OF INTEREST}

The authors declare that they have no conflict of interest.

\section{ABBREVIATIONS}

PG: Panax ginseng; PL: Placebo Trial; RPE: Rate Of Perceived Exertion; FFA: Free Fatty Acid; SOD: Superoxide-Dismutase, LPO: Lipid Peroxidase; LA: Plasma Lactate; TBARS: Thiobarbituric Acid Reactive Substances.

\section{REFERENCES}

1. Ping FWD, Keong CC, Bandyopadhyay A. Effects of acute supplementation of Panax ginseng on endurance running in a hot and humid environment. Ind $J$ Med Res. 2011;133(1):96-102.

2. Kitts DD, Hu C. Efficacy and safety of ginseng. Public Health Nutr. 2000;3(4a):473-85.

3. Bucci LR. Selected herbals and human exercise performance. Am J Clin Nutr. $2000 ; 72(2): 624 S-36 S$

4. Talbott SM. A guide to understanding dietary supplements in Philadelphia: Lippincott Williams and Wilkins. Haworth Press, New York. 1995.

5. Pieralisi G, Ripari P, Vecchiet L. Effects of a standardized ginseng extract combined with dimethylaminoethanol bitartrate, vitamins, minerals and trace elements on physical performance during exercise. Clin Ther. 1991;13(3):373-82.

6. Cherdrungsi P, Rungreong K. Effect of standardized ginseng extract and exercise training on aerobic and anaerobic exercise capacities in human. J Ginseng Res. 1995;19(2):93-100.

7. Allen JD, McLung J, Nelson AG, Welsch M. Ginseng supplementation does not enhance healthy young adults' peak aerobic exercise performance. J Am Coll Nutr. 1998;17(5):462-6.

8. Forgo I, Schimert G. The duration of effect of the standardized ginseng extract G115 in healthy competitive athletes. Notabene Med. 1985;15:636-40.

9. Engels HJ, Said JM, Wirth JC. Failure of chronic ginseng supplementation to affect work performance and energy metabolism in healthy adult females. Nutr Res. 1996;16(8):1295-305

10. Dupont WD, Plummer WD. Power and sample size calculations for studies involving linear regression. Control Clin Trials. 1998;19(6):589-601.

11. Williams $\mathrm{MH}$. Nutrition for health, fitness and sport, $6^{\text {th }}$ Ed. Boston: Mc GrawHill. 2002.

12. Lowry $\mathrm{OH}$, Rosebrough NJ, Farr AL, Randall RJ. Protein measurement with the folin phenol reagent. J Biol Chem. 1951;193:265-75.

13. Kunst A, Draeger B, Ziegenhorn J. Metabolites 1: Carbohydrates. Methods of enzymatic analysis. $3^{\text {rd }}$ Ed. 1984;163-72.

14. Alan WU. Tietz Clinical Guide to LaboratoryTests. $4^{\text {th }}$ Ed. Philadelphia: WB Saunders Company. 2006;444-51.

15. Sapin R, Galudec VL, Gasser F, Pinget M, Grucker D. Elecsys insulin assay: Free insulin determination and the absence of cross-reactivity with insulin lispro. Clin Chem. 2001;47(3):602-5.

16. Kwon DY, Rhee JS. A simple and rapid colorimetric method for determination of free fatty acids for lipase assay. J Am Oil Chem Soc. 1986;63(1):89-92.

17. Lowry R, Tinsley I. Rapid colorimetric determination of free fatty acids. J Am Oil Chem Soc. 1976;53(7):470-2.

18. Marklund S, Marklund G. Involvement of the superoxide anion radical in the autoxidation of pyrogallol and a convenient assay for superoxide dismutase. Eur J Biochem. 1974;47(3):469-74.

19. Claiborne A. Catalase activity. In: Greenwald RA. CRC Handbook of methods for oxygen radical research, $3^{\text {rd }}$ Ed. Florida: CRC Press. 1985;283-4.

20. Wright JR, Colby HD, Miles PR. Cytosolic factors that affect microsomal lipid peroxidation in lung and liver. Arch Biochem Biophys. 1981;206(2):296-304

21. Ellman GL. Tissue sulfhydryl groups. Arch Biochem Biophys. 1959;82(1):70-7.

22. Barker SB, Summerson WH. The colorimetric determination of lactic acid in biological material. J Biol Chem. 1941;138:535-54.

23. Kim SH, Park KS, Chang MJ, Sung JH. Effects of Panax ginseng extract on exercise-induced oxidative stress. J Sports Med Phys Fitness. 2005;45(2):178-82.

24. Lee ES, Yang YJ, Lee JH, Yoon YS. Effect of high-dose ginsenoside complex (UG0712) supplementation on physical performance of healthy adults during a 12-week supervised exercise program: A randomized placebo-controlled clinical trial. J Ginseng Res. 2018;42(2):192-8.

25. Oliynyk S, Oh S. Actoprotective effect of ginseng: Improving mental and physical performance. J Ginseng Res. 2013;37(2):144-66.

26. Caldwell LK, Dupont WH, Beeler MK, Post EM, Barnhart EC, Hardesty VH, et al. The effects of a Korean ginseng, GINST15, on perceptual effort, psychomotor performance and physical performance in men and women. J Sports Sci Med. 2018;17(1):92-100.

27. Vuksan V, Sung MK, Sievenpiper JL, Stavro PM, Jenkins AL, DiBuono M, et al. Korean red ginseng (Panax ginseng) improves glucose and insulin regulation in well-controlled, type 2 diabetes: Results of a randomized, double-blind, placebo-controlled study of efficacy and safety. Nutr Metab Cardiovasc Dis. 2008;18(1):46-56

28. Reay JL, Scholey AB, Milne A, Fenwick J, Kennedy DO. Panax ginseng has no effects on indices of glucose regulation following acute and chronic ingestion in healthy volunteers. Br J Nutr. 2009;101(11):1673-8.

29. Jung HL, Kwak HE, Kim SS, Kim YC, Lee CD, Byurn HK, et al. Effects of Panax ginseng supplementation on muscle damage and inflammation after uphill treadmill running in humans. Am J Clin Med. 2011;39(3):441-50.

30. Bai L, Gao J, Wei F, Zhao J, Wang D, Wei J. Therapeutic potential of ginsenosides as an adjuvant treatment for diabetes. Front Pharmacol. 2018;9:1-14.

31. Lee $\mathrm{NH}$, Jung $\mathrm{HC}$, Lee $\mathrm{S}$. Red ginseng as an ergogenic aid: A systematic review of clinical trials. J Exerc Nutr Biochem. 2016;20(4):13-9.

32. Lee JY, Jin HJ, Park JW, Jung SK, Jang JY, Park HS. A case of Korean ginsenginduced anaphylaxis confirmed by open oral challenge and basophil activation test. Allergy Asthma Immunol Res. 2012;4(2):110-1. 